\title{
Research on the Influence of
} Traceability Information of Fresh Agricultural Products on Consumers'
Purchasing Behavior

\author{
Mengjun Yu, Xiuxia Yan, Jikai Wang \\ School of Management, Shandong University of Technology, Zibo, China \\ Email: 740210582@qq.com, sdlgdyxx2021@163.com,951536752@qq.com
}

How to cite this paper: Yu, M. J., Yan, X. X., \& Wang, J. K. (2021). Research on the Influence of Traceability Information of Fresh Agricultural Products on Consumers' Purchasing Behavior. Open Journal of Business and Management, 9, 2370-2388.

https://doi.org/10.4236/ojbm.2021.95128

Received: August 19, 2021

Accepted: September 13, 2021

Published: September 16, 2021

Copyright () 2021 by author(s) and Scientific Research Publishing Inc. This work is licensed under the Creative Commons Attribution International License (CC BY 4.0).

http://creativecommons.org/licenses/by/4.0/

\section{(c) (i) Open Access}

\begin{abstract}
Based on the composite perspective of product, consumer cognition and consumer emotion, this paper establishes a research model of consumer purchase behavior of agricultural products traceability information. Through the questionnaire survey of urban consumers in a city, the correlation analysis and regression analysis are used to calculate the influence coefficient of various kinds of traceability information on consumer purchase behavior. This paper empirically analyzes consumers' preference for traceability information of fresh agricultural products. The results show that: the group of online purchase of traceable fresh agricultural products is mainly young women aged 26 - 35; most of them have higher education level and stable income level. Traceability information, food safety, product display, shopping experience, safety value, information value and economic value of fresh agricultural products have significant positive effects on customers' purchasing behavior. Finally, it is proposed that enterprises should improve the traceability information of fresh agricultural products according to the needs of customers, so as to avoid the high cost caused by the pursuit of too much traceability information.
\end{abstract}

\section{Keywords}

Fresh Agricultural Products, Traceability Information, Perceived Value, Regression Analysis

\section{Introduction}

In recent years, the issue of food safety has become a hot topic of urgent con- 
cern. In order to ensure food safety, China has accelerated the construction of a food traceability system. In 2009, it introduced the first agricultural product quality traceability management method. Subsequently, local government departments at all levels have successively issued more than 70 relevant regulations on agricultural product quality traceability. However, since fresh agricultural products are a typical "experience commodity", it is difficult to judge their freshness and safety characteristics from their appearance, so the traceability information of agricultural products plays an important role. This article will construct a research model for the impact of traceable information of fresh agricultural products on consumer purchasing behavior, and use correlation analysis and regression analysis to calculate the impact index of various traceable information on consumer purchasing behavior, and understand consumers' influence on consumer purchasing behavior, understand consumers' preference for traceability information, select useful information conducive to improving the traceability information system, provide targeted opinions for enterprises to improve the traceability information system, and avoid excessive.

\section{Literature Review}

In practice, large supermarket chains such as JD.com, Taobao, Wal-Mart, Hema Fresh Food, e-commerce platforms and some listed agricultural products companies have successively established fresh agricultural products traceability systems. With the construction of the traceability system of agricultural products in the industrial sector, the academic community has also carried out relevant research on the traceability system of agricultural products, and has achieved certain research results in the consumption of fresh agricultural products, the traceability of fresh agricultural products, and the impact of the traceability information of fresh agricultural products on consumers' purchase behavior. Regarding the consumption of fresh agricultural products, Feng Yanfang analyzed the impact of the price attributes of fresh agricultural products on consumption from the perspective of the mechanism of price leverage of fresh agricultural products (Feng, 2019); Nie Wenjing et al. used Joint Analysis and Clustering Analysis and Multiple Logit Models have analyzed the impact of the quality attributes of fresh agricultural products on consumption (Nie, Li, \& Hua, 2016); Qianwen Liu et al. established an online retailer pricing and ordering model by studying the delivery speed and quality preference of consumers. Regarding the traceability of fresh agricultural products (Liu, Zhang, \& Zhao, 2017), Jun Li et al. aimed to solve the problem of information traceability of fresh agricultural products by constructing a one-stop logistics management information system for fresh agricultural products (Li, Gao, \& Liu, 2017). Wang Yupeng proposed to improve the traceability information of fresh agricultural products by using blockchain technology to improve the service quality of fresh food e-commerce enterprises. Regarding the impact of the traceability information of fresh agri- 
cultural products on consumer purchase behavior (Wang, 2020), Feng Yanfang et al. studied the mechanism of the influence of the traceability information of fresh agricultural products on the purchase intention of consumers, Put forward a targeted scheme to improve consumers' purchase intention (Feng, 2020). Liu Zengjin et al. used empirical research on the impact of traceability trust variables on consumer behavior, and made suggestions for strengthening food safety supervision (Liu, Qiao, \& Wang, 2016).

Based on different perspectives, the existing domestic literature adopts different methods to conduct standardized analysis and empirical analysis of traceable agricultural product consumer behavior, and has obtained rich research results, which provide reference ideas and experience for the research of this article. However, through combing the literature, it is found that there are large differences in the width, depth, and accuracy of traceability information attached to traceable agricultural products. It is necessary to clarify what is necessary and very valuable information for consumers in order to locate useful information.

\section{Research Model and Research Hypothesis}

\subsection{Variable Determination}

This article defines dependent variables and independent variables based on the SOR model, namely "stimulus-individual physiology, psychology-response".

Zhang Bei et al. took subtropical fruits as an example, and believed that product traceability, safety, information quality, product display, trust and preference are important factors that affect customers' perceived value (Zhang \& Lin, 2015). Qi Fangzhong believes that the three dimensions of the origin environment, product variety and process detection in the traceability information of agricultural products have an impact on the perceived value (Qi, Chen, \& Wang, 2021). Combining the research results of scholars, the theme of this article, and the SOR model, this article uses the four dimensions of traceability information, food safety, product display, and shopping experience as environmental stimulus variables, that is, the dependent variable in the regression analysis, and the consumer's perceived value is taken as Independent variable.

According to the theory of customer perceived value, this article regards perceived value as a cognitive variable, which is defined as six variables: safety value, information value, functional value, social value, emotional value, and economic value (Sweeney \& Soutar, 2001). Li Zongwei et al. analyzed the impact of product perception value, service perception value and social perception value on consumer purchasing decision by studying the driving effect of perceived value on purchasing decision (Li, Zhang, \& Luan, 2017). Sylvain Charlebois analyzed the impact of safety value, information value, functional value, and economic value on consumer behavior through the research on the traceability information of dairy products (Charlebois \& Haratifar, 2015). From the research results of scholars, it can be seen that perceived value is a cognitive variable, and con- 
sumer behavior is a behavioral response, that is, perceived value is used as the dependent variable of regression analysis, and consumer behavior is an independent variable.

\subsection{Research Hypothesis}

1) Traceability information and perceived value

Traceability information refers to the digital information monitored through the Internet, telephone, SMS, POS and other means during production, transportation, processing and sales. For enterprises, the traceability information of fresh agricultural products can help enterprises standardize and standardize production and processing processes. While improving the safety and quality of products, it can also enhance the company's brand benefits and increase corporate sales. For consumers, traceability information reduces information asymmetry in the commodity transaction process and enhances the authenticity of commodity information. In the event of a quality safety accident, consumers can quickly find the problematic link and actively and effectively protect their rights. Previous studies have shown that traceability information has a positive effect on the improvement of consumer purchasing power (Hsu, Chang, \& Lin, 2019). Therefore, this article puts forward the following assumptions.

H1: Traceability information positively affects perceived value.

2) Food safety and perceived value

The safety of fresh agricultural products with traceable information means that they have passed quality and safety certification in the process of planting, picking, packaging, storage, transportation, sales and consumption, and comply with national food safety standards. With the improvement of the living standards of Chinese residents, food safety issues have become the focus of consumers' attention. Therefore, food safety may become an important motivation for the establishment and improvement of the traceability system of fresh agricultural products (Yin, Wang, \& Lv, 2017). Therefore, this article puts forward the following assumptions.

H2: Food safety positively affects perceived value.

3) Product display and perceived value

Through a good product display, the characteristics of traceable fresh agricultural products can be fully demonstrated in terms of appearance packaging, freshness, nutritional content, cooking methods, and edible effects of fresh agricultural products, and consumers can feel the traceable fresh agricultural products more intuitively. The quality and safety of agricultural products makes consumers pay more attention to traceable fresh agricultural products, which in turn generates a desire to purchase and completes the purchase behavior. Previous studies have shown that the product display of traceable fresh agricultural products has a positive impact on the perceived value of consumers (Han \& Zhang, 2019). Therefore, this article puts forward the following assumptions.

H3: Product display positively affects perceived value. 
4) Shopping experience and perceived value

Fresh agricultural products with traceable information can provide consumers with strong food safety guarantee in terms of shopping experience, and even if food safety problems occur, they can also provide consumers with good rights protection conditions. At the same time, this kind of fresh agricultural products requires more complete information equipment, which can provide more commodity information. This kind of products can also meet consumers' high-end shopping needs, give consumers more satisfaction in obtaining high-quality products, and give consumers a better shopping experience. Previous studies have shown that traceable fresh agricultural products can positively affect consumers. The perceived value of (Gonçalves, Lourenço, \& Silva, 2016). Therefore, this article puts forward the following assumptions.

H4: Product display positively affects perceived value.

5) Perceived value and purchasing behavior

This article regards perceived value as a cognitive variable, and defines it as six variables: safety value, information value, functional value, social value, emotional value, and economic value. Propose corresponding research hypotheses: H5: Functional value positively affects purchase behavior (Gonçalves, Lourenço, \& Silva, 2016); H6: Safety value positively affects purchase behavior (Hua, 2010); H7: Emotional value positively affects purchase behavior (Zhong, 2013); H8: Society Value positively affects purchase behavior (Zhang, 2015); H9: Economic value positively affects purchase behavior (Zhang, 2015); H10: Information value positively affects purchase behavior (Fu, 2020).

\subsection{Theoretical Model}

To sum up, traceability information of fresh agricultural products, food safety, product display, and shopping experience are important factors for consumers to obtain good perceived value and generate purchase motivation and purchase behavior. Perceived value has a direct impact on purchase behavior from six aspects: functional value, safety value, emotional value, social value, economic value, and information value. Thus, the establishment of a consumer behavior research model is as follows Figure 1.

\section{Research and Design}

\subsection{Questionnaire Design and Measurement Indicators}

This research mainly uses questionnaire surveys, and the questionnaire survey method is currently the most common survey method used by scholars in their research. This article reads a large number of relevant documents, draws on the questionnaire designed by the predecessors for the same variables, and adjusts and revises the characteristics of fresh agricultural products with traceable information; then invites producers, sellers, some experts and consumers of fresh agricultural products The participants discussed the questionnaires of the scale, 


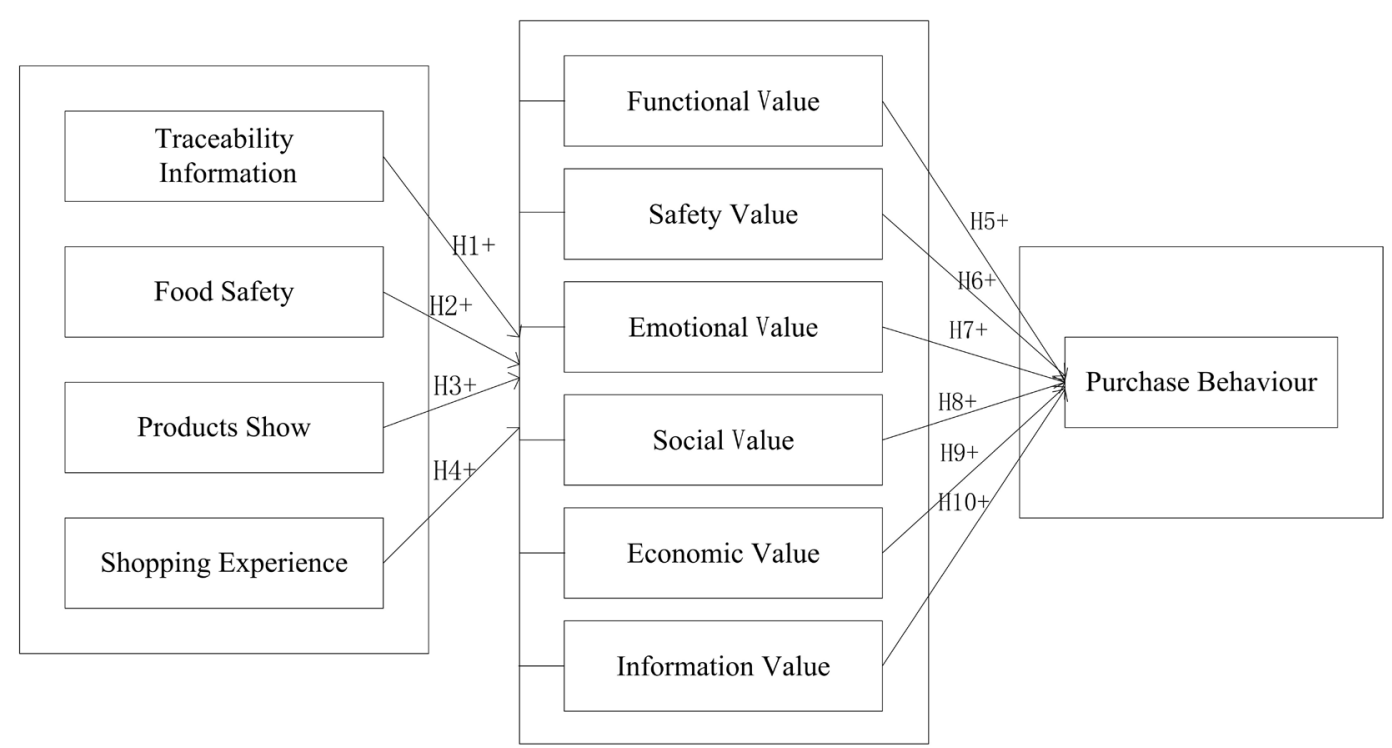

Figure 1. Traceable information and consumer behavior model.

checked and modified inappropriate questionnaires, and obtained the final questionnaire, which ensured the validity of the questionnaire design.

This questionnaire measures the various variables involved in the research by designing different topics, so as to achieve the purpose of improving the reliability and validity of the questionnaire. This article divides the questionnaire into two parts. The first part is the basic information of consumers who have purchased fresh agricultural products with traceable information. The second part is a specific investigation of the impact of traceable information on the purchase behavior of fresh agricultural products on consumers, mainly measuring the research content of the six influencing factors in the previous article. The questionnaire items are all multiple-choice questions. The second part of the questionnaire uses a Likert five-level scale ( 1 means strongly disagree; 2 means disagree; 3 means general; 4 means agree; 5 means strongly agree), questionnaire survey. The indicators and items are shown in Table 1.

\subsection{Sample Selection and Data Collection}

\section{1) Sample selection}

The subjects of this study are people in a city who have purchased traceable fresh agricultural products online. According to the sample size calculation formula (1), the confidence coefficient $C=0.7$, standard deviation $\sigma=0.6$ and accuracy $p=0.03$ are specified, and the sample size is 196. The questionnaires in this study were distributed mainly on the questionnaire star, and the questionnaires were spread out through social platforms such as mutual community and circle of friends. From March 2, 2021 to March 22, a total of 660 questionnaires were collected. Among them, there are 614 valid questionnaires, with an effective rate of $93 \%$. 
Table 1. Measurement indicators and specific items.

\begin{tabular}{|c|c|}
\hline Measurement Standard & Measurement Item \\
\hline \multirow{2}{*}{ Safety Value } & Q1 Traceable information plays a positive role in ensuring the safety of vegetables and other foods \\
\hline & Q2 Traceable information is more secure than the quality and safety of fresh products with non-traceable information \\
\hline \multirow[t]{2}{*}{ Information Value } & $\begin{array}{l}\text { Q3 Fresh products with traceable information that have been tested by authoritative organizations throughout the } \\
\text { process are safe }\end{array}$ \\
\hline & Q4 Traceable information allows me to better understand the product characteristics of fresh products \\
\hline \multirow{2}{*}{ Functional Value } & Q5 Traceable information allows me to obtain higher quality fresh products \\
\hline & Q6 Purchasing fresh products with traceable information can give me an excellent shopping experience \\
\hline \multirow{2}{*}{ Social Value } & Q7 Purchasing fresh products with traceable information can give me a good impression with my relatives and friends \\
\hline & Q8 Purchasing fresh products with traceable information can make people feel that I have taste \\
\hline \multirow{2}{*}{ Emotional Value } & Q9 I am more happy to buy fresh products with traceable information \\
\hline & Q10 Purchasing fresh products with traceable information makes me feel safer to eat \\
\hline \multirow[b]{2}{*}{ Economic Value } & $\begin{array}{l}\text { Q11 When there are both ordinary fresh products and fresh products with traceable information in the market, and } \\
\text { the prices of the two are the same, consumers are more willing to buy fresh products with traceable information }\end{array}$ \\
\hline & $\begin{array}{l}\text { Q12 When there are both ordinary fresh products and fresh products with traceable information in the market, the } \\
\text { price of fresh products with traceable information is higher than that of ordinary fresh products, and consumers are } \\
\text { more willing to buy fresh products with traceable information }\end{array}$ \\
\hline Customer & Q13 I would recommend others to buy fresh products with traceable information \\
\hline Purchase Intention & Q14 When I buy fresh products, I will consider buying fresh products with traceable information \\
\hline
\end{tabular}

$$
n=\frac{C^{2} \cdot \sigma^{2}}{p^{2}}
$$

2) Data collection

Taking into account factors such as time, epidemic and labor costs, and the characteristics of the survey objects, the data collection in this article is mainly distributed in the form of online questionnaires. In order to make the data more authentic and credible, this article sets data collection standards. First, incomplete questionnaires will not be accepted; second, when filling in the questionnaire, all options are the same and not accepted; third, checking the questionnaire filling time, less than 1 minute will not be accepted; fourth, in the questionnaire If $50 \%$ of the data comes from the same age group, then redundant data for that age group must be eliminated to ensure the wide range of data sources.

\section{Empirical Analysis Results}

\subsection{Descriptive Statistics}

In this study, women accounted for $62.87 \%$; the age was mainly 26 - 35 years old, accounting for $36.81 \%$. Consumers with undergraduate and junior college education accounted for a relatively large proportion, among which consumers with a higher level of education. The number of people accounted for $89.09 \%$, and the 
income group of 3000 - 5000 yuan accounted for a relatively large group, $50.65 \%$, and the occupation was mainly office workers, accounting for $44.46 \%$. The statistical results are shown in Table 2. Among the consumer groups who buy fresh products, fresh products with traceable information are a new type of consumer product. Because the young people have a relatively strong ability to accept new things and this part of the population is already working, there is a certain degree of economic development. As a result, there are more people buying fresh products with traceable information than other groups.

In this study, $46.58 \%$ of consumers would choose to buy traceable fresh agricultural products every two to three weeks; followed by $36.48 \%$ of consumers would choose to buy goods once a week; slightly fewer people would buy multiple times a week, accounting for $12.7 \%$; the crowd who rarely buys is the least, at $4.23 \%$. The vast majority of consumers buy fresh agricultural products from the fresh market, accounting for $92.35 \%$; the second largest purchase method is from large supermarket chains, accounting for $78.01 \%$; followed by community services click-to-purchase, accounting for $61.56 \%$; followed by purchases from online shopping platforms such as Taobao and Pinduoduo, which accounted for

Table 2. Descriptive statistical results of the basic conditions of the sample.

\begin{tabular}{|c|c|c|c|}
\hline Variable & Options & Frequency & percentage $(\%)$ \\
\hline \multirow{2}{*}{ Gender } & Male & 228 & 37.13 \\
\hline & Female & 386 & 62.87 \\
\hline \multirow{5}{*}{ Age } & 18 - 25 years old & 99 & 16.12 \\
\hline & 26 - 35 years old & 226 & 36.81 \\
\hline & 36 - 45 years old & 128 & 20.85 \\
\hline & 46 - 55 years old & 82 & 13.36 \\
\hline & Over 55 years old & 79 & 12.87 \\
\hline \multirow{4}{*}{ Education Level } & High school and below & 67 & 10.91 \\
\hline & Specialist & 188 & 30.62 \\
\hline & Undergraduate & 247 & 40.23 \\
\hline & Postgraduate and above & 122 & 18.24 \\
\hline \multirow{4}{*}{ Profession } & Students & 446 & 18.08 \\
\hline & Office workers & 350 & 44.46 \\
\hline & Freelance & 170 & 19.87 \\
\hline & Others & 53 & 17.59 \\
\hline \multirow{5}{*}{ Income } & Below 1000 yuan & 10 & 1.63 \\
\hline & 1000 - 3000 yuan & 90 & 14.66 \\
\hline & $3000-5000$ yuan & 311 & 50.65 \\
\hline & 5000 - 10,000 yuan & 163 & 26.55 \\
\hline & Above 10,000 yuan & 40 & 6.51 \\
\hline
\end{tabular}


a relatively small proportion of $44.95 \%$; finally, purchases from take-out platforms such as Meituan and Ele.me and other channels. They accounted for $29.15 \%$ and $8.79 \%$ respectively. It can be seen from these data that consumers do not purchase fresh agricultural products with traceable information frequently, and most people still choose to buy fresh agricultural products for daily needs offline. Therefore, to develop the traceable fresh agricultural products market, we should start with the traditional offline purchase methods.

The food safety of fresh agricultural products is still the most worrying issue for consumers. $70.03 \%$ of consumers who are not worried about the safety of fresh agricultural products purchased daily, and only $29.97 \%$ of consumers believe that the daily fresh agricultural products purchased are safe Therefore, it is very necessary to promote fresh agricultural products with traceable information to meet consumer requirements for food safety issues.

The way consumers understand food safety information is mainly through online media, television broadcasting, and government propaganda, accounting for $83.22 \%, 77.85 \%$, and $77.52 \%$ respectively, followed by friend notifications and business advertisements, which accounted for respectively. Compared with $66.94 \%$ and $47.23 \%$, a small number of people learn about food safety information through newspapers, magazines and other channels, accounting for $31.43 \%$ and $3.42 \%$ respectively. Propaganda of food safety information should be carried out from three aspects: network media, television broadcasting, and government propaganda.

The traceability information of fresh agricultural products that consumers most want to know is whether the product is genetically modified or organic, accounting for $90.55 \%$, followed by harvest/slaughter date, pesticide/veterinary drug use, environmental conditions in the production area, and product testing reports, respectively accounted for $65.64 \%, 64.01 \%, 63.52 \%, 50.81 \%$; less attention is paid to variety characteristics, nutrient composition test reports, product certification reports, cooking methods and light/temperature/humidity conditions during growth, which account for $25.57 \%$ respectively, $24.76 \%, 22.31 \%$, $16.61 \%, 15.96 \%$. From these data, it can be seen that consumers are more concerned about whether the fresh products are genetically modified or organic, the date of harvest/slaughter, the use of pesticides/veterinary drugs, and the environmental conditions of the product origin.

\subsection{Measurement Model Analysis}

1) Descriptive statistics of variables

Use SPSS23.0 software to perform descriptive statistical processing on all measurable variables to calculate the mean, standard deviation, skewness and kurtosis of each measurable variable, as shown in Table 3. The average number is greater than 3 , indicating that the overall perception of the surveyed for each measurable variable is greater than 3 . It can be found from the table that the standard deviation of each research variable is between 0.6 - 1 , and the degree of 
Table 3. Descriptive statistics of variables.

\begin{tabular}{|c|c|c|c|c|c|c|}
\hline Variable & Item & Sample size & Mean & Standard deviation & Skewness & Kurtosis \\
\hline \multirow{2}{*}{ Safety Value } & Q1 & \multirow{2}{*}{614} & 4.259 & 0.8604 & -0.926 & 0.119 \\
\hline & Q2 & & 4.35 & 0.8772 & -1.399 & 1.6 \\
\hline \multirow{2}{*}{ Information Value } & Q3 & \multirow{2}{*}{614} & 4.064 & 0.754 & -0.861 & 1.163 \\
\hline & Q4 & & 3.751 & 0.6499 & -0.775 & 0.945 \\
\hline \multirow{2}{*}{ Functional Value } & Q5 & \multirow{2}{*}{614} & 3.87 & 0.8253 & -0.802 & 1.252 \\
\hline & Q6 & & 4.039 & 0.9095 & -0.86 & 0.657 \\
\hline \multirow{2}{*}{ Social Value } & Q7 & \multirow{2}{*}{614} & 3.164 & 0.8062 & 0.011 & 0.447 \\
\hline & Q8 & & 3.166 & 0.7759 & 0.124 & 0.535 \\
\hline \multirow{2}{*}{ Emotional Value } & Q9 & \multirow{2}{*}{614} & 3.2 & 0.8281 & -0.734 & 0.582 \\
\hline & Q10 & & 3.668 & 0.7644 & -0.676 & 1.308 \\
\hline \multirow{2}{*}{ Economic Value } & Q11 & \multirow{2}{*}{614} & 3.868 & 0.9544 & -1.214 & 1.399 \\
\hline & Q12 & & 3.104 & 0.7462 & -0.384 & 0.908 \\
\hline \multirow{2}{*}{$\begin{array}{c}\text { Customer } \\
\text { Purchase Behavior }\end{array}$} & Q13 & \multirow{2}{*}{614} & 4.068 & 0.7078 & -0.735 & 1.218 \\
\hline & Q14 & & 4.41 & 0.8762 & -1.63 & 2.634 \\
\hline \multicolumn{2}{|c|}{ Valid N (list status) } & & & 614 & & \\
\hline
\end{tabular}

dispersion between the data is not small, indicating that the stability of each measurable variable is better. The absolute values of skewness and kurtosis of a single variable are both less than 3 , indicating that the univariate normal distribution test is qualified and meets the research requirements.

2) Reliability analysis

Use SPSS23.0 to analyze the reliability, consistency and stability of the results measured by the questionnaire. The results are shown in Table 4. The Cronbach Alpha coefficients of all variables and the overall questionnaire are all greater than 0.7 , which shows that the reliability of the questionnaire is good and it has the value of further research.

3) Validity analysis

Validity test is to test the degree of agreement between the questionnaire and the expected measurement target, that is, consistency. The KMO value and Bartlett's sphericity test performed on the sample data are shown in Table 5. The results show that the validity KMO of the questionnaire in this study is 0.916, which is greater than 0.8 , and the validity is good. The significance of Bartlett's sphericity test is infinitely close to 0 , reject the null hypothesis, suitable for factor analysis, the questionnaire has good applicability, so it can be analyzed in the next step.

4) Analysis of differences

According to the results of the independent sample t-test in Table 6, it can be seen that the perceived value of fresh products with traceability information differs in gender, and the difference test is significantly less than 0.05 , indicating 
Table 4. Reliability analysis.

\begin{tabular}{cc}
\hline Variable & Kronbach Alpha Coefficient \\
\hline Safety Value & 0.890 \\
Information Value & 0.714 \\
Functional Value & 0.777 \\
Social Value & 0.982 \\
Emotional Value & 0.804 \\
Economic Value & 0.784 \\
Customer Purchase Behavior & 0.709
\end{tabular}

Table 5. Validity analysis.

\begin{tabular}{ccc}
\hline \multicolumn{2}{c}{ KMO sampling suitability number } & 0.916 \\
\hline & Approximate chi-square & $11,237.58$ \\
Bartlett's sphericity test & Degrees of freedom & 191 \\
& Significance & 0.000 \\
\hline
\end{tabular}

Table 6. Analysis of gender differences in various dimensions.

\begin{tabular}{|c|c|c|c|c|c|c|}
\hline Perceived Value & Gender & Number of cases & Average & Standard deviation & $\mathrm{t}$ & sig \\
\hline \multirow[b]{2}{*}{ Safety Value } & Male & 228 & 7.8947 & 1.68888 & \multirow[b]{2}{*}{-8.439} & \multirow[b]{2}{*}{0} \\
\hline & Female & 386 & 9.0311 & 1.47325 & & \\
\hline \multirow{3}{*}{ Information Value } & Male & 228 & 7.5395 & 1.45815 & \multirow{3}{*}{-3.95} & \multirow{3}{*}{0} \\
\hline & & & & & & \\
\hline & Female & 386 & 7.9767 & 1.0627 & & \\
\hline \multirow{3}{*}{ Functional Value } & Male & 228 & 7.636 & 1.41544 & \multirow{3}{*}{-3.786} & \multirow{3}{*}{0} \\
\hline & & & & & & \\
\hline & Female & 386 & 8.0699 & 1.29646 & & \\
\hline \multirow[b]{2}{*}{ Social Value } & Male & 228 & 5.8684 & 1.69484 & \multirow[b]{2}{*}{-5.505} & \multirow[b]{2}{*}{0} \\
\hline & Female & 386 & 6.6036 & 142187 & & \\
\hline \multirow{3}{*}{ Emotional Value } & Male & 228 & 6.6009 & 1.19595 & \multirow{3}{*}{-4.303} & \multirow{3}{*}{0} \\
\hline & & & & & & \\
\hline & Female & 386 & 7.0259 & 1.15965 & & \\
\hline \multirow{2}{*}{ Economic Value } & Male & 228 & 6.5614 & 1.66612 & \multirow{2}{*}{-5.041} & \multirow{2}{*}{0} \\
\hline & Female & 386 & 7.215 & 1.33791 & & \\
\hline
\end{tabular}

that consumers of different genders can trace fresh products the perceived value of information differs in gender. According to the mean, it can be seen that the mean evaluation of women is slightly higher than that of men.

In the same way, conduct a differentiated analysis of age, occupation, and educational background. Among the six dimensions of the perceived value of fresh products with traceable information, there are differences in age, occupation, and educational background: the average evaluation of the 26 - 35-year-old consumer group is slightly higher than that of other age groups; the occupation 
is office workers the average evaluation of the consumer group is slightly higher than that of other occupations; the average evaluation of the consumer group with a bachelor degree is slightly higher than other education.

5) Correlation analysis

In this paper, Pearson's simple correlation coefficient is used to compare the correlation coefficient between variables to test the strength of the correlation between variables. The correlation between security value, information value, functional value, social value, emotional value, economic value and customer purchase intention is shown in Table 7. It can be seen from Table 7 that the correlation coefficients between safety value, information value, functional value, emotional value, economic value and customer purchasing behavior are all greater than 0.5 , and the significance level is 0 , which is less than the theoretical significance level of 0.01 . It shows that security value, information value, functional value, emotional value, economic value and customer purchase behavior have a certain correlation, among which the correlation coefficient between economic value and customer purchase intention is the highest. However, correlation analysis only proves that there is no correlation between social value and customers' purchase intention, and cannot test the causal relationship and the degree of mutual influence between other variables. Therefore, regression analysis is needed to further verify whether there is a causal relationship between variables and the degree of mutual influence.

6) Regression analysis

Regression analysis is to use the observed data as the basis to study their internal

Table 7. Correlation coefficient table of each influencing factor.

\begin{tabular}{|c|c|c|c|c|c|c|c|c|}
\hline Perceived Value & & Safety Value & $\begin{array}{l}\text { Information } \\
\text { Value }\end{array}$ & $\begin{array}{l}\text { Functional } \\
\text { Value }\end{array}$ & Social Value & $\begin{array}{c}\text { Emotional } \\
\text { Value }\end{array}$ & $\begin{array}{c}\text { Economic } \\
\text { Value }\end{array}$ & Safety Value \\
\hline \multirow{2}{*}{ Safety Value } & Pearson correlation & 1.000 & & & & & & \\
\hline & Significance (bilateral) & 0.000 & & & & & & \\
\hline \multirow{2}{*}{ Information Value } & Pearson correlation & $0.600^{* *}$ & 1.000 & & & & & \\
\hline & Significance (bilateral) & 0.000 & & & & & & \\
\hline \multirow{2}{*}{ Functional Value } & Pearson correlation & $0.672^{* *}$ & $0.458^{* *}$ & 1.000 & & & & \\
\hline & Significance (bilateral) & 0.000 & 0.000 & & & & & \\
\hline \multirow{2}{*}{ Social Value } & Pearson correlation & $0.177^{\star *}$ & -0.008 & -0.04 & 1.000 & & & \\
\hline & Significance (bilateral) & 0.000 & 0.000 & 0.000 & & & & \\
\hline \multirow{2}{*}{ Emotional Value } & Pearson correlation & $0.636^{* *}$ & $0.551^{* *}$ & $0.722^{* *}$ & 0.035 & 1.000 & & \\
\hline & Significance (bilateral) & 0.000 & 0.000 & 0.000 & 0.000 & & & \\
\hline \multirow{2}{*}{ Economic Value } & Pearson correlation & $0.697^{* *}$ & $0.842^{* *}$ & $0.414^{* *}$ & 0.032 & $0.494^{* *}$ & 1.000 & \\
\hline & Significance (bilateral) & 0.000 & 0.000 & 0.000 & 0.0000 & 0.000 & & \multirow{3}{*}{1.000} \\
\hline Customer & Pearson correlation & $0.779^{* *}$ & $0.873^{* *}$ & $0.511^{* *}$ & -0.027 & $0.572^{\star *}$ & $0.909^{* *}$ & \\
\hline Purchase Behavior & Significance (bilateral) & 0.000 & 0.000 & 0.000 & 0.000 & 0.000 & 0.000 & \\
\hline
\end{tabular}


relationships, and to analyze the degree of influence of each influencing factor on the result among multiple influencing factors, and use the degree of influence to indicate the degree of importance of the factor. This study established a multiple linear regression model of the impact of fresh agricultural products with traceable information on consumer purchasing behavior.

Taking traceability information, food safety, product display, and shopping experience as independent variables, and customer's perceived value as a dependent variable, using the linear stepping analysis method in SPSS23.0 to perform regression analysis, the results show that traceability information, food safety, and product display have entered in the final model, it shows that there may be a causal relationship between traceability information, food safety, product display, and customer perceived value. Therefore, the regression model can be established as:

$Y=a_{0}+b_{1} \times$ Traceability Information $+b_{2} \times$ Food Safety $+b_{3} \times$ Products Show $+\varepsilon$

where $a_{0}$ represents the intercept, represents the coefficient of the $b_{i}$ independent variable, represents the $\varepsilon$ residual, and $Y$ represents the dependent variable. The regression results are shown in Table 8-10. According to Table 8, the DW value is 1.754 , which is between 1.5 and 2.5 , indicating that the samples are independent; the certainty coefficient $\left(\mathrm{R}^{2}\right)$ of the equation is 0.987 , and the adjusted $\left(R^{2}\right)$ is 0.987 , indicating that the regression equation can be $98.7 \%$ Explains the change of the dependent variable to the degree, and the degree of explanation is better. In addition, it can be seen from Table 9 that $\mathrm{F}$ is 3161.151, and the significance is less than 0.05 , indicating that the regression model obtained in this analysis exists. It can be seen from Table 10 that the tolerances are both greater than 0.1 and the VIF is less than 5 , indicating that there is no obvious multicollinearity problem; the standardization coefficients for traceability information, food safety, and product display are $0.387,0.474,0.222$, and the significance values are all Less than 0.05 , indicating that the regression effect is significant, the regression model is:

Table 8. Model summary.

\begin{tabular}{cccccc}
\hline Model & $\mathrm{R}$ & $\mathrm{R}^{2}$ & Adjust $\mathrm{R}^{2}$ & Standard estimate error & $\mathrm{D}-\mathrm{W}$ \\
\hline & 0.969 & 0.939 & 0.939 & 0.30708 & 1.956 \\
\hline
\end{tabular}

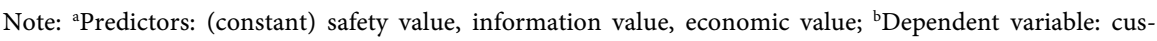
tomer perceived value.

Table 9. ANOVA analysis of variance.

\begin{tabular}{cccccc}
\hline Model & Sum of Square & Degree of freedom & Mean square & F & Significance \\
\hline Regression & 894.293 & 3 & 298.098 & 3161.151 & 0.000 \\
Residual error & 58.089 & 616 & 0.94 & & \\
Total & 952.381 & 619 & & & \\
\hline
\end{tabular}

Note: ${ }^{a}$ Predictive variables: (constant) traceability information, food safety, product display; ${ }^{b}$ Dependent variable: customer perceived value. 
Table 10. Regression analysis model coefficients.

\begin{tabular}{ccccccccc}
\hline \multirow{2}{*}{ Model } & \multicolumn{2}{c}{$\begin{array}{c}\text { Unstandardized } \\
\text { Coefficient }\end{array}$} & $\begin{array}{c}\text { Standardization } \\
\text { Factor }\end{array}$ & $\mathrm{t}$ & Significance & \multicolumn{2}{c}{$\begin{array}{c}\text { Collinearity } \\
\text { Statistics }\end{array}$} \\
\cline { 2 - 4 } & $\mathrm{B}$ & Standard Error & Beta & & & Tolerance & VIF \\
\hline Constant & 0.686 & 0.073 & & 9.443 & 0.000 & & \\
$\begin{array}{c}\text { Traceability } \\
\text { Information }\end{array}$ & 0.331 & 0.012 & 0.387 & 27.602 & 0.000 & 0.503 & 1.989 \\
Food Safety & 0.318 & 0.011 & 0.474 & 28.084 & 0.000 & 0.348 & 2.872 \\
Products Show & 0.177 & 0.012 & 0.222 & 14.672 & 0.000 & 0.431 & 2.321 \\
\hline
\end{tabular}

Note: aPredictive variables: (constant) traceability information, food safety, product display; ${ }^{\mathrm{D} D e p e n d e n t}$ variable: customer perceived value.

$$
\begin{aligned}
Y= & 0.686+* 0.387 \times \text { Traceability Information }+* 0.474 \times \text { Food Safety } \\
& +* 0.222 \times \text { Products Show }
\end{aligned}
$$

That is, in the traceable information of fresh agricultural products, traceability information, food safety, and product display have a significant positive impact on customer perceived value, and traceability information has the greatest impact on customer perceived value.

Taking safety value, information value, functional value, emotional value, and economic value as independent variables, and customer purchasing behavior as dependent variables, using the linear stepping analysis method in SPSS23.0 for regression analysis, the results indicate safety value, information value, and economic value. Value enters into the final model, indicating that there may be a causal relationship between security value, information value, economic value and customer purchasing behavior.

Therefore, the regression model can be established as:

$$
Y=a_{0}+b_{1} \times \text { Safety Value }+b_{2} \times \text { Information Value }+b_{3} \times \text { Economic Value }+\varepsilon
$$

The regression results are shown in Table 11-13. According to Table 11, the $\mathrm{D}-\mathrm{W}$ value is 1.971 , which is between 1.5 and 2.5 , indicating independence between samples; the certainty coefficient $\left(\mathrm{R}^{2}\right)$ of the equation is 0.905 , and the adjusted $\left(R^{2}\right)$ is 0.904 , indicating that the regression equation can be $90.4 \% \mathrm{Ex}$ plains the change of the dependent variable to the degree, and the degree of explanation is better. In addition, it can be seen from Table 12 that $\mathrm{F}$ is 1931.723, and the significance is less than 0.05 , indicating that the regression model obtained in this analysis exists. It can be seen from Table 13 that the tolerances are both greater than 0.1 and VIF are both less than 5, indicating that there is no obvious multicollinearity problem; the standardization coefficients of safety value, information value, and economic value are $0.418,0.273,0.357$, and the significance values are all Less than 0.05 , indicating that the regression effect is significant, the regression model is:

$$
\begin{aligned}
Y= & 0.842+* 0.418 \times \text { Safety Value }+* 0.273 \times \text { Information Value } \\
& +* 0.357 \times \text { Economic Value }
\end{aligned}
$$


Table 11. Model summary.

\begin{tabular}{|c|c|c|c|c|c|}
\hline Model & $\mathrm{R}$ & $\mathrm{R}^{2}$ & Adjust $\mathrm{R}^{2}$ & Standard estimate error & $\mathrm{D}-\mathrm{W}$ \\
\hline & 0.951 & 0.905 & 0.904 & 0.421 & 1.971 \\
\hline
\end{tabular}
tomer perceived value.

Table 12. ANOVA analysis of variance.

\begin{tabular}{cccccc}
\hline Model & Sum of Square & Degree of freedom & Mean square & F & Significance \\
\hline Regression & 1025.301 & 3 & 341.767 & 1931.723 & 0.000 \\
Residual error & 107.923 & 610 & 0.177 & & \\
Total & 1133.225 & 613 & & & \\
\hline
\end{tabular}

Note: aPredictors: (constant) safety value, information value, economic value; ${ }^{b}$ Dependent variable: customer perceived value.

Table 13. Regression analysis model coefficients.

\begin{tabular}{|c|c|c|c|c|c|c|c|}
\hline \multirow{2}{*}{ Model } & \multicolumn{2}{|c|}{$\begin{array}{l}\text { Unstandardized } \\
\text { Coefficient }\end{array}$} & \multirow{2}{*}{$\begin{array}{c}\begin{array}{c}\text { Standardization } \\
\text { Factor }\end{array} \\
\text { Beta }\end{array}$} & \multirow[t]{2}{*}{$\mathrm{t}$} & \multirow{2}{*}{ Significance } & \multicolumn{2}{|c|}{$\begin{array}{l}\text { Collinearity } \\
\text { Statistics }\end{array}$} \\
\hline & B & Standard Error & & & & Tolerance & VIF \\
\hline Constant & 0.842 & 0.119 & & 7.084 & 0.000 & & \\
\hline $\begin{array}{l}\text { Traceability } \\
\text { Information }\end{array}$ & 0.378 & 0.023 & 0.418 & 16.151 & 0.000 & 0.234 & 4.282 \\
\hline Food Safety & 0.225 & 0.014 & 0.273 & 15.686 & 0.000 & 0.514 & 1.946 \\
\hline Products Show & 0.391 & 0.025 & 0.357 & 15.417 & 0.000 & 0.29 & 3.444 \\
\hline
\end{tabular}

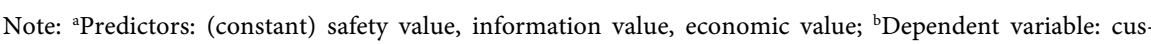
tomer perceived value.

That is, among the perceived value of fresh agricultural products, safety value, information value, and economic value have a significant positive influence on customer purchasing behavior, and safety value has the greatest impact on customer purchasing behavior.

\section{Conclusions and Recommendations}

\subsection{Conclusion}

In general, the traceability information of agricultural products can be used as an external stimulus to influence consumers' behavior by increasing their perceived value, thereby enhancing consumers' willingness to buy. Among the four dimensions of agricultural product traceability information, the four dimensions of traceability information, food safety, product display, and shopping experience have significant effects on perceived value. It can be seen that if the fresh agricultural products are traceable, the product will have a good perceived value, which will prompt consumers to purchase desire and implement purchase behavior. Second, food safety has a positive impact on the purchase motivation of 
traceable fresh agricultural products. Fresh agricultural products are the daily necessities of consumers, and they are mainly fresh and raw food. Therefore, with the improvement of consumers' living standards, consumers pay more attention to the edible safety of fresh agricultural products. Traceable fresh agricultural products can reduce information asymmetry and reduce food safety risks. Therefore, improving the traceability information system of fresh agricultural products can increase consumers' willingness to purchase and facilitate purchase decisions. Product display is another important factor affecting the purchase motivation of traceable fresh agricultural products. This shows that creating an excellent sales atmosphere for traceable fresh agricultural products can attract consumers' attention to such products, enhance consumers' understanding of such products, and make it easier to form a comprehensive and objective understanding of such products and then promote consumers' purchase motivation. In addition, a good shopping experience can also encourage consumers to purchase motives to a certain extent.

Among the six dimensions of perceived value, the three dimensions of security value, information value, and economic value have a significant impact on purchasing behavior, while emotional value, functional value, and social value have no significant impact on purchasing behavior. This result may have the following three reasons: First, the price of traceable fresh agricultural products is too high, and the high price will reduce the perception of emotional value to a certain extent. Second, there is a situation where the functional value is affected and offset by the information value. The information value perceived by consumers includes the understanding of the freshness, taste and nutrition of agricultural products, resulting in the duplication and offset of the information value and the functional value. Third, because the market penetration rate of traceable fresh agricultural products is not high, it cannot provide effective help for consumers to improve their personal social status and enhance their social skills in the social process.

On the whole, in the 14 traceable information compiled and summarized in this article, consumers have a positive attitude towards obtaining various traceable information of agricultural products. Among them, the traceability information of the top 5 agricultural products that consumers most want to know are: whether they are genetically modified or organic products, harvest/slaughter date, pesticide/veterinary drug use, environmental conditions of the product origin, product inspection reports, and the last 5 kinds of traceability information are: light/temperature/humidity during growth, cooking method, product certification report, nutrient content test report and variety characteristics. In addition, the personal characteristics of consumers will affect their preferences. From the perspective of gender, the number of women buying agricultural products with traceability information is much higher than that of men, and women are more eager to obtain perceived value; from the perspective of age, mainly the consumer group refers to the young group of 26 - 35 years old; from 
the perspective of occupation and income level, office workers with a certain economic level are more willing to buy fresh products with traceable information; in terms of academic level, a bachelor with a high degree of education , Specialty consumer groups are more willing to buy fresh products with traceable information.

\subsection{Suggestion}

Enterprises should improve the traceability information of fresh agricultural products in response to customer needs. While improving the information, they should also reduce information redundancy and avoid the high cost of pursuing too much traceability information, thereby enhancing corporate efficiency.

1) Production enterprises

For production enterprises, the producer is the source of the fresh product traceability system. High-quality fresh products are the fundamental guarantee for the long-term development of the entire traceability system, and it is also an important link to improve the traceability information system. The recorded traceability information is also the most concerned information of consumers. Strengthen quality supervision and record the quality and safety status of commodities in the traceability system to establish brand credibility. Manufacturers need to further improve related technologies, reduce traceability costs, and provide traceable information including whether they are genetically modified or organic products, harvest/slaughter date, pesticide/veterinary drug use, environmental conditions of product origin, product testing reports and other traceable information.

2) Sales enterprise

As a group of direct contact with consumers, sellers are the most important part of sales. The quality of sales services directly affects their own income and product sales. Sellers guarantee that in the wholesale and retail links of fresh products to ensure that the information in each link is complete and transferable. Sellers should also pay attention to the improvement of their sales skills, provide consumers with excellent commodity display forms, and use big data to push accurate commodity types to consumers of different genders, educational backgrounds and ages, so as to meet the shopping needs of fresh agricultural products of all kinds of people. While maximizing its own interests, it can also guarantee the long-term development of the traceability information system for fresh agricultural products.

\section{Conflicts of Interest}

The authors declare no conflicts of interest regarding the publication of this paper.

\section{References}

Charlebois, S., \& Haratifar, S. (2015). The Perceived Value of Dairy Product Traceability 
in Modern Society: An Exploratory Study. Journal of Dairy Science, 98, 3514-3525. https://doi.org/10.3168/jds.2014-9247

Feng, Y. F. (2019). Research on Poverty Alleviation Model and Strategy of Fresh Agricultural Products Consumption-Analysis Based on the Price Leverage Mechanism of Fresh Agricultural Products. Price Theory and Practice, No. 8, 42-45.

Feng, Y. F. (2020). Research on Online Shopping Pricing Strategy of Fresh Agricultural Products-Analysis from the Perspective of Consumers' Online Shopping Willingness. Price Theory and Practice, No. 7, 137-140.

Fu, H. (2020). Can Social Capital of Virtual Brand Community Affect Consumers' Premium Purchase Behavior? Enterprise Economy, No. 1, 19-25.

Gonçalves, H. M., Lourenço, T. F., \& Silva, G. M. (2016). Green Buying Behavior and the Theory of Consumption Values: A Fuzzy-Set Approach. Journal of Business Research, 69, 1484-1491. https://doi.org/10.1016/j.jbusres.2015.10.129

Han, W. W., \& Zhang, H. (2019). Research on the Impact of Product Service Portfolio Elements on Perceived Value. Nankai Management Review, No. 4, 95-102.

Hsu, S. Y., Chang, C.-C., \& Lin, T. T. (2019). Triple Bottom Line Model and Food Safety in Organic Food and Conventional Food in Affecting Perceived Value and Purchase Intentions. British Food Journal, 121, 333-346. https://doi.org/10.1108/BFJ-07-2017-0403

Hua, Y. M. (2010). Analysis of Mobile Phone Purchase Behavior of Migrant Workers Based on Customer Value Theory. China's Rural Economy, No. 9, 82-90 + 96.

Li, J., Gao, H. M., \& Liu, Y. C. (2017). Requirement Analysis for the One-Stop Logistics Management of Fresh Agricultural Products. Journal of Physics: Conference Series, 887, Article ID: 012004. https://doi.org/10.1088/1742-6596/887/1/012004

Li, Z. W., Zhang, Y. H., \& Luan, D. Q. (2017). What Factors Affect Consumers' Online Purchase Decisions-Driving Role of Customer Perceived Value. Management Review, No. 8, 136-146.

Liu, Q. W., Zhang, S., \& Zhao, Y. (2017). Online-Retailer Pricing and Order Strategies Based on the Quality of Fresh Agricultural Products and Distribution Preference of Consumers. International Journal of Internet Manufacturing and Services, 4, 222.

Liu, Z. J., Qiao, J., \& Wang, X. H. (2016). The Impact of Brand Traceability Trust on Consumers' Food Consumption Behavior-Taking Pork Products as an Example. Technical Economy, No. 5, 104-111.

Nie, W. J., Li, T. P., \& Hua, S. C. (2016). Consumer Preference for Quality Attributes of Fresh Agricultural Products and Analysis of Influencing Factors: The Case of Apple. Agricultural Technology and Economy, No. 9, 60-71.

Qi, F. Z., Chen, X. Y., \& Wang, J. Y. (2021). Research on Consumer Behavior and Preference of Traceability Information of Fresh Agricultural Products. Science and Technology and Economy, No. 1, 46-50.

Sweeney, J. C., \& Soutar, G. N. (2001). Consumer Perceived Value: The Development of a Multiple Item Scale. Journal of Retailing, 77, 203-220.

https://doi.org/10.1037/t56704-000

Wang, Y. P. (2020). Thoughts on Improving the Quality of Fresh e-Commerce Services from the Perspective of Blockchain. Business Economic Research, No. 14, 92-95.

Yin, S. J., Wang, X. N., \& Lv, S. S. (2017). Brand, Certification and Consumer Trust Tendency-Taking Organic Milk as an Example. Journal of Huazhong Agricultural University (Social Science Edition), No. 4, 45-54 + 147. 
Zhang, B., \& Lin, J. B. (2015). Traceable Subtropical Fruit Consumption Behavior Paradigm in the Context of Quality and Safety: The Regulatory Role of Purchase Experience. Management Review, No. 8, 176-189+212.

Zhang, J. H. (2015). Research on Customer Purchase Intention Based on Wechat Marketing. Ph.D. Thesis, Shanghai University of Engineering and Technology.

Zhong, K. (2013). Research on the Impact of Online Consumers' Perceived Value on Purchase Intention. Ph.D. Thesis, Liaoning University. 